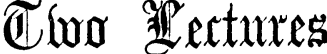

INTRODUCTORY TO THE CLINICAL COURSE ON

\section{THE DISEASES OF WOMEN AND CHILDREN.}

DELIVERED AT THE MIDDLESEX HOSPITAL.

BY

W I L L I A M O. P R I EST LEY, M. D.,

PHYSICIAN-ACCOUCHEUR TO THE HOSPITAL, AND LECTURER ON MIDWIFERY IN THE COLLEGE.

LECTURE II (concluded from p. 163).

The diagnosis of diseases peculiar to women is beset by various difficulties; and some of these are of so special and singular a character that only by the exercise of considerable tact, and the acquisition of that knowledge which experience alone teaches, can they be successfully overcome. Some suggestions indicating the nature of these difficulties may, nevertheless, be useful to you.

1. The medical attendant is frequently embarrassed or misled in his endeavour to form an opinion concerning the real condition of a female patient, by being able to obtain only an imperfect history of the case and of the symptoms actually present. That natural reserve which is very properly regarded as the grace of modest women, very often leads female patients to suppress information which it is very necessary for the medical man to possess. It can scarcely excite wonder that unmarried women should be indisposed to speak of inconveniences arising out of derangements in the sexual organs; but the repugnance to speak on any such matters is sometimes equally strong in the married woman or matron. It is repeatedly found by those who pay much attention to female diseases, that in the enumeration of symptoms by the patient some of the most important are passed over until elicited by careful cross-examination. Often, from an indisposition to confide her secret to a medical man, a patient will submit to great inconvenience or pain for a prolonged period, and sometimes, indeed, will allow disease to progress well nigh to a fatal termination without making a complaint.

I saw a patient some time ago who had been suffering for years with dragging pain at the loins and great inconvenience in walking, caused by the presence of a large pediculated tumour attached to the labia pudendi. The tumour was perfectly benign in character, and, when discovered, was removed at once by a slight operation. And yet for years this patient had studiously abstained from mentioning the presence of the tumour, and had had various prescriptions for pain in the back and other symptoms produced by it. A second patient, affected with a tumour growing from the cervix uteri, which was large enough to project beyond the external parts, allowed herself to be treated for leucorrhœa for a considerable period by a medical practitioner, and subsequently married, without confessing the true cause of her symptoms; and was only induced to speak at last on the subject to her medical man by her husband threatening to leave her.

An old and intelligent practitioner, who had an extensive practice in Lincolnshire, but is lately de- ceased, once told me of a curious illustration of this reticence in a female patient, which proved a severe lesson to him when commencing practice. He attended a young lady apparently suffering from a severe inflammation of the bowels or peritoneum, and who eventually died. Only when his patient was in a dying condition did she confess to the presence of a tumour in the groin, which proved to be a strangulated hernia. Had the medical man known about this earlier, it might probably have admitted of such treatment as would have prevented the fatal issue.

But, even in those cases where a full and complete history has been elicited, so far as the symptoms are concerned, the medical attendant is often placed at great disadvantage in forming an opinion as to the exact nature of the ailment, because-

2 . Of the great objections which female patients commonly have to submit to a necessary physical examination. You need scarcely to be informed that the mere history of functional derangement in any organ of the body gives no sufficient clue to the precise nature of the physical changes which are being produced in that organ. A patient suffering from pruritus vulvæ, for example, may have this symptom developed as the result of a constitutional affection connected perhaps with some particular diathesis; but this form of irritation is occasionally associated with some of the graver forms of uterine disease, of which, as yet, perhaps it is the only urgent symptom. A patient affected in this way was prescribed for repeatedly, without submitting to an examination, the necessity of which was represented to her; and, when the examination was at last permitted, she was found to have the mons veneris and labia majora infested with pediculi, which had given rise to the intolerable itching complained of.

The term leucorrhœa, by which is meant an unusual discharge of mucous or muco-purulent fluid from the vagina, is frequently employed as though it were itself a disease; but in reality it is only a symptom of some morbid affection existing in the generative organs. It may result merely from unusual relaxation of the vagina, and a too copious secretion of the ordinary mucus lubricating the passages; but it also attends, and indeed is commonly one of the most prominent symptoms in, ulceration of the cervix uteri, whether benign or malignant in character; inflammation of the uterine cavity, or uterine catarrh; pelvic abscess or fistula opening into the vagina; and cases of cauliflower excrescence of the cervix uteri.

Menorrhagia, again, or a too copious menstrual flow, may arise from any cause by which the ovaries or uterus become abnormally congested; and in these cases, probably, very little change can be detected in the organs by examination. But menorrhagia is also one of the most prominent symptoms which attend uterine polypi and fibrous tumours; and it is often the very first indication of serious disease in cases where carcinoma uteri is already far advanced.

3. From the numerous sympathetic derangements which complicate the diseases of women, and those of the reproductive organs in particular, the attention of the medical attendant is apt to be diverted away from the true seat of the malady, and fixed on some point, of less importance. The pain experienced in the knee by those aftlicted with hip-joint 
disease, and the pain in the testicle which often accompanies disease of the kidney, are examples of sympathetic derangement met with in general practice. Commonly associated with diseases of the uterus and its appendages, are instances of the same kind not less remarkable. The pain attending disease in the ovary or uterus may be experienced principally in the mammary glands. Dr. Simpson tells us that he was once consulted by a lady who suffered from pain in the mamme, and had been assiduously treated by various local and gencral remedies, in the hope of relieving it. She was subsequently found to have a slow corroding carcinoma of the uterus, upon which the mammary pain depended, and which, at the time of examination, had destroyed almost the whole tissue of the cervix. Pain referred to the lumbar or sicral regions in the back is very often produced by some morbid lesion in the pelvis; and sympathetic vomiting, palpitation of the heart, and various forms of neuralgia, may have the same origin. Pain over a small extent of surface just below the left breast, and known as inframammary pain, is nearly as frequent in connexion with uterine disease as pain in the shoulder is in connexion with hepatic derangement.

4. From certain peculiarities in the constitution of women more immediately connected with the nervous system, severe diseases are so closely simulated that it is often very difficult to distinguish between the spurious and the real. You may be called to see a young female patient who has to all appearance an acute and dangerous attack of peritonitis. There may be exquisite tenderness to pressure, a certain amount of swelling, and other indications of this serious affection, and yet the attack may be one of an essentially hysterical character. In these cases, the pulse is not likely to have that rapidity and force which you might expect if inflammation were present; and if you can divert the attention of your patient for a moment from the tender abdomen, she bears, in all probability, pressure without flinching. Hip-joint disease may be simulated just in the same way, and the counterfeit affection may be detected in a similar manner.

Perhaps the most curious of all the imitative diseases are those conditions named respectively hysteric tympanitis and spurious pregnancy. These affections have often been mistaken for ovarian or uterine tumours or for genuine pregnancy. The abdomen is projected forward, as if it contained a solid tumour or gravid uterus; and if there is much fat in the subcutaneous tissue, the muscles of the abdomen, being unusually tense, yield a sensation to the hand very similar to that experienced when a solid mass is really present. In cases of this kind, the abdomen has in fact been tapped, and on several occasions been laid open by incision, for the purpose of excising an ovarian tumour, when none was present. The use of percussion ought, of course, in these cases, to do much in clearing up doubts concerning the nature of the abdominal swelling; but more conclusive still is the evidence afforded when we administer chloroform to the patient. If the case be one of hysteric tympanitis or spurious pregnancy, uncomplicated with solid tumour, the swelling entirely disappears when deep anrsthesia is induced, but it reappears as consciousness returns.

5. The diagnosis of disease in women is further complicated by the fact that a large proportion of them are attended by no appreciable change of structure in the part affected. When children are ill, their complaints are chiefly corporeal, and a sort of general ratio may be observed between the development of symptoms and organic lesion in some part or organ of the body; but in women we find a large class of morbid affections, many of them very painful and even alarming in character, which, in the present state of our knowledge, cannot be associated with any alteration in the part implicated. The irritable uterus described by Dr. Gooch is a painful affection of the womb, atterided by no increase of heat or in the size of the organ, and no appreciable deviation from the physical characters it presents in health can be detected.

Some of the forms of neuralgia are, no doubt, produced by sympathy with derangement in some distant organ; others, again, admit no such explanation; and no organic disease can be detected at the seat of pain. A peculiar group of symptoms in females, which, for want of a better explanation, are said to arise from "spinal irritation", may be enumerated in the same category. A patient suffering from this affection complains of severe pain in the back, and perhaps also in other parts of the body. An inability or unwillingness to walk creeps on ; and the lower limbs, for want of use, gradually waste. No organic disease is usually found to account for these symptoms ; and the most careful examination after death fails to detect any change in the spinal cord or elsewhere. It would be wrong, nevertheless, in these cases, to suppose that the sensations experienced by the patient are fanciful or imaginary. Her pain is probably none the less real because a medical man cannot find an organic cause for it ; and, although much good may be done by encouragement, none will result from harsher treatment.

6. But lastly - the physician in investigating the diseases of women has constantly to be upon his guard lest deception and imposition be practised upon him. This is a difficulty in diagnosis altogether peculiar of its kind, which belongs specially to the pathology of females. In studying infantile pathology, the practitioner may be at fault from an inability to comprehend that language of signs by which alone the indications of disease are manifested in young children; but that language is at least truthful, if rightly comprehended. In women the case is sometimes widely different; for, instead of using the gift of speech the better to direct the physician in his medical inquiries, they will employ it sedulously for the purpose of deceiving him. I by no means wish to be understood as impugning the veracity of women generally; but cases of wilful deception in female patients are so commonly met with, that I am anxious to put you on your guard against them. I do not now allude to those instances in which a woman has an obvious motive for deception, as in the persistent denial of pregnancy by the unmarried, in face of the strongest evidence of its existence; nor do I allude to those cases in which a poor female patient is so possessed by an illusion concerning her bodily health, that she endeavours to impress upon the medical attendant a belief firmly rooted in her own mind. The instances to which I allude are even more singular, and apparently altogether purposeless. I saw, with Dr. Dobell, not long ago, a patient, who, besides marked hysterical symptoms, had a moveable tumour in the right lumbar region, which we be- 
lieved to be a so called "floating kidney." She dwelt with a morbid tenacity on her various symptoms, and had an apparent gratification in stating that the several remedies prescribed for her, were followed by no improvement. Her attention having been specially fixed on some derangement of the urinary organs, by the discovery of the moveable kidney, she brought one day to Dr. Dobell a number of small angular bodies, which she affirmed were calculi passed from her bladder. These calculi turned out on careful examination to be small flint pebbles.

Some months ago, I saw a middle aged lady from the country, who had, according to her own account, been suffering from menorrhagia for a prolonged period. I could find no organic disease sufficient to account for the hæmorrhage, and the same report was given by other physicians, who had been consulted on the case. Some weeks after she left London, her family medical attendant sent me a packet containing a piece of fibrous looking substance which the lady had given to him, with the intimation that it had escaped from the vagina at the menstrual period, and that she had frequently passed masses of a like character. On examination with the microscope it proved to be muscular fibre of meat, in which the transverse striæ were uncommonly distinct, and it had probably been cooked, as the fibrillæ were separated with unusual facility.

In a third case, which occurred some years ago, during my connection with St. George's and St. James's Dispensary, a young unmarried woman brought the testicle of some domestic animal, with the assertion that it had come from her womb; and, by way of removing the doubts I expressed as to the accuracy of her statement, brought me the fellow testicle at my next sitting.

The late Dr. Richard Mackenzie of Edinburgh, had a lady patient who was in the habit of thrusting needles into her foot, and then submitting to a surgical operation for their removal; I believe no fewer than ten needles were cut out in this way from one foot, and then a remark having caught the patient's ear as to the singularity of their always being in the same foot, the next needle appeared in the opposite limb.

Professor Bennett, of Edinburgh, had under his care a woman who brought him pieces of fresh animal bladder, as having been passed by herself. She was found to have procured them from the shambles for the purpose of deceiving him.

But the most curious and incomprehensible of all, is the history of a patient kindly communicated to me by Mr. Page, of Carlisle, in the following words-

"A young woman applied at the Infirmary, with a very unhealthy looking ulcer at the upper part of the sternum; it appeared to resist all treatment, and spread with such extreme rapidity, that it seemed to me she must be doing something to increase it. I therefore had it covered in such a way that she could not get at it, and under the most simple treatment it speedily healed. A year or more after, she again applied at the Infirmary. She said she had a gathering at the end of her finger. There was a sinus leading to the bone, which I found was dead, and I proposed its removal. To this she would not consent, and she ceased her attendance. I found that she afterwards went to Liverpool, where partial am- putation of the finger was performed; but, the wound not healing, she was admitted into the Infirmary and amputation of the forearm was performed, I believe by the late Mr. Bickersteth, the wound having then extended to the hand, and assumed much of a malignant aspect. For a time all went on well, but at length the same appearances presented themselves in the stump, and amputation of the arm above the elbow was resorted to. She at length left the Infirmary at Liverpool, the stump being healed or nearly so, and returned to Carlisle. Here the same appearances of disease were again developed, and she was admitted into the workhouse, and amputation at the shoulder-joint was performed. The wound I believe healed, and she went home, but shortly she complained of ulceration of the stump, and she applied to me at the Infirmary again. The cicatrix at the shoulder was now the seat of a most foul and extensive sore, and she said she was sure there was disease of the shoulder blade. I ordered her a chloride of zinc lotion, and told her to come on the following day. She did so, and at once producing a small parcel she said I was mistaken in supposing there was no disease of the bone, for that while she was washing the wound last night, two pieces came away, and she presented me with two large clean pieces, apparently cut through the shaft of a leg of mutton. Without telling her that I did not believe her, I desired her to come into the Infirmary on the following day that she might be better attended to. She came as desired,-the ulcerated cushion of stump having in it a transverse wound fully three inches in length, and not less than an inch deep, which had evidently been inflicted with some blunt instrument; she said she found it the night before after she went to bed. I ordered her to bed and had her arm bound to her body; in three weeks the shoulder was perfectly healed. A few days after her arm was released, I was visiting the ward at night. As I passed her bed I observed that her left eye was swollen. I inquired the cause, when she said she thought she must have got some dust off the wall in it, but that it was not painful. On everting the eyelid I found a piece of lime plaster more than the eighth of an inch in diameter carefully secreted. From that time she lived a life of the extremest poverty. She attended after at the Infirmary on account of menorrhagia, which was always looked upon with suspicion, and about two years ago she died of phthisis, never having admitted her deceptions to any one. The motives which induced this unfortunate creature so to subject herself to torture, are certainly not to be divined. It was not for the sake of sympathy; for she had none. She lived in a wretched home with her father and a sister, who suspected her of malingering, and who, when she had the wounds, often made her sleep in an outhouse, as the odour was unbearable."

Examples of this description are indeed comparatively numerous, and you may very naturally ask, what is the explanation of them? A satisfactory answer in the present state of our knowledge is, I fear, not readily forthcoming. In some cases, no doubt, the tendency to deceive arises out of a morbid craving for sympathy. A patient suffers; her medical man fails to discover any adequate cause for her illness; and to enlist his interest, she is induced first to exaggerate and then to deceive. But there are cases for which this explanation is not sufficient, and which 
are only explicable by supposing the presence of some mental disease. In nearly all the instances of this kind we are able to trace some disorder or derangement connected with the organs of reproduction, and it is on this account that they are classed among the phenomena which are termed hysterical. With a full knowledge of the facts I have enumerated, and called upon constantly to encounter them, it can scarcely be wondered at, that medical men are habitually cautious in receiving evidence from females, and are more incredulous than others of any unusual or marvellous phenomenon exhibited by women, and particularly by young woman ; more especially if any indications are present of impaired bodily health, such as I have alluded to. With the exercise of all possible skill and care, they occasionally find great difficulty in solving some of the complex problems of disease presented by this class of patients, and are sometimes constrained to admit that success in treatment has rather been in proportion to an effect produced on the mind, than the physical effect of remedies prescribed.

In conclusion, I trust that in indicating some of the difficulties you have to encounter in studying the diseases of women, I have not discouraged you. You will have gathered from what has been said, that minute observation, painstaking, and cautious investigation, tact and delicacy of feeling, are indispensable to successful practice in this department ; but, with the exercise of these, the difficulties are for the most part surmountable.

\section{gllurstrations}

oF

\section{HOSPITAL PRACTICE: METROPOLITAN AND PROVINOIAL.}

\section{ST. MARY'S HOSPITAL.}

\section{A CASE OF PERSistent EPISTAXis.}

Under the care of E. H. SIEvE KING, M.D.

THE following case presents several features of interest, in relation to the origin, the immediate source, and the treatment of the hæmorrhage.

J. S., aged 37, a married man, and at the first applica tion for relief a toll-collector, subsequently a mes senger, tall, well built, but anæmiated, came under Dr. Sieveking's care, March 14,1856 , on account of epistaxis, to which he had been subject for about a year. The hæmorrhage had notably increased in frequency and amount for the preceding two or three weeks. The previous history was to the effect that, when about eight years old, he had ague; when 22 , small-pox; and when 31 , low fever. Besides that, he was nearly blind in the left eje from an injury received when about 20 years of age. The hereditary influences were much against him, since his mother, brother, and two sisters have died phthisical. He never saw any blue (purpuric) spots on his body; there was no trace of pulmonary or of cardiac disease, nor was there any enlargement of the spleen. The patient had been subject to sick head. ache. The hrmorrhage had occurred daily for the last six days, at the time of application. He had two days previously felt a snapping in the left side of the head; the largest epistaxis had lasted an hour. He complained of great weakness, which he attributed to the hæmor rhage; he was afraid to blow his nose, because it immediately brought on the epistaxis. The bowels were costive; the pulse 100 , full. The hæmorrhage appeared to come from the left nostril only, the lining membrane of which was red from intense congestion, while the opposite side was normal. There was no appearance of polypus, and he could breathe freely through both nostrils. The patient attributed the hæmorrhage to cold, caught in his occupation as toll-collector on Hungerford Bridge, in which capacity he was exposed to a constant draught impinging upon the left side of the body : there were, however, no signs of catarrhal or rheumatic affection. During the visit hæmorrhage came on, which was immediately arrested by adopting the plan recommended by Négrier many years ago, of elevating the arms above the head. He was ordered to snuff up the liquor aluminis, and to take every morning an ounce and a half of white mixture (sulphate and carbonate of magnesia). March 18th. The report is, less epistaxis; the last occurred yesterday morning. The white mixture was repeated; and he was ordered to have an ounce of quina mixture, with half a drachm of dilute sulphuric acid, three times a day. March 25 th. He twice had short attacks of epistaxis since last visit; has had a good dinner every day. There were three slight attacks up to the 1st April, when he ceased attending; the treatment being continued as above. $\mathrm{He}$ remained free from epistaxis for six weeks. On the 10th May it returned, and occurred on four consecutive days, rendering him very nervous, the immediate cause on this occasion being an annoyance by a set of drunken men. The bowels were costive; there was much pain on the upper part of the left parietal bone; the pulse 80 , and strong. The acid quinine mixture and laxatives were resumed; and counterirritation to the neck, followed by an issue on the arm with mezereon bark, were adopted with marked benefit. The hæmorrhage was always at once controlled by the remedies, but sooner or later it recurred when they were omitted. A new symptom now (May 20th 1856 ) supervened in the shape of severe pain at the epigastrium before the commencement of the epistaxis. Gallic and tannic acids and krameria were employed; but a steady perseverance in the internal use of quinine, and the external application of the liquor aluminis compositus, seemed to promise most success. On the 27 th June, there had been no hæmorrhage for thirteen days, and the patient reported himself much stronger, July 18th. No hæmorrhage for thirty days, till four days ago, when, while sitting still, he felt a tingling in the nose, which caused a sneeze, since which there has been slight hæmorrhage daily; he complains of a sensation of scalding or itching as if there were ice inside, confined to the left side of the head and neck. The mezereon was now applied to the left upper arm as a counterirritant, the other remedies, with compound colocynth pill, being continued. July 25th. 'The hæmorrhage having continued daily, and there being now gnawing pains in the region of the left kidney, two grains of acetate of lead were given three times a day in addition to the quinine. Arrest of the hæmorrhage followed these measures; and after the 19th August the patient ceased attending.

In October 1859 , he again came under treatment, on account of a return of the complaint. The anæmia was very marked, and the general and local symptoms were essentially the same as on the former occasions. There was nothing abnormal in the microscopic appearances of the blood; there was no purpura, enlarged spleen, or other organic disease traceable. The application of nitrate of silver to the nostril, the administration of sulphuric acid and buchu internally, failed to arrest the hæmorrhage. The infusion of digitalis with tincture of the sesquichloride of iron was then given, together with five-grain pills of gallic acid; and it is inferred, from his ceasing to attend, that the disorder was checked. Since then he has not again presented himself. 